\title{
EDUCATION INTERNATIONALIZATION
}

\section{RATIONALES OF INTERNATIONALIZATION: RETHINKING ACADEMIC MOBILITY}

\section{VERA ZABOTKINA}

Russian State University for the Humanities, Russia

Keywords: Mobility, employability, (work) placements, traineeship, virtual mobility, internationalization

\begin{abstract}
The paper addresses traditional and new models of academic mobility developed within Erasmus Mundus projects ("Triple I" and "Aurora") at the Russian State University for the Humanities. We try to answer the question regarding the meaning of academic mobility in the 21st century. The focus is on the dynamics of academic mobility. Among the new models emphasis will be made on student mobility combined with traineeship, (work) placements, mobility between universities and enterprises and virtual mobility. The paper discuses on the problem of interconnection between mobility and employability of graduates. We will also attempt to analyze the quality as well as the main learning outcomes in such mobilities. We will end up with posing the multi-modal prospective to academic mobility.
\end{abstract}

Source: Zabotkina V., 2013. "Rationales of internationalization: Rethinking academic mobility", Perspectives of Innovations, Economics \& Business, Vol.13(4), pp.59-66,

http://dx.doi.org/10.15208/pieb.2013.19

\section{Introduction}

Internationalization as a key concept of modern education aims at training students to be employable in the context of world economy. In other words internationalization should be part of the whole process of education so that the students should be able to apply their knowledge at international level. They should be competitive in order to function effectively in the global world. Internationalization should be a key component of the university mission. One of the tools of implementation of internationalization strategy is academic mobility.

What does academic mobility mean on the 21st century? Among the multiplicity of different patterns of academic mobility the new model is emerging at the moment. This new type of mobility should help to

\footnotetext{
* The article was reported in PRADEC Interdisciplinary Conference Proceedings.

"Internationalisation in Higher Education: Evaluating Concepts, Challenges and Strategies", Prague, April 25-26, 2013 
bridge the gap between education and employability and should include work placements.

According to OECD, critical skills for the most innovative jobs in the 21st century are willingness to question ideas, come up with new ideas and solutions and present them in audience, alertness to opportunities, analytical thinking, and abilities to write reports and documents, speak a foreign language and perform under pressure*. The most demanded skills, however, are transversal skills and competences. In order to be employable internationally the students should develop intercultural communication competence. "Graduates who have international experience are highly employable because they have demonstrated that they have drive, resilience and inter-cultural sensitivities as well as language skills" (Coleman, 2011).

Substantial and robust evidence exists that, over and above the generic links between language study and graduate employability, academic mobility including work experience abroad provide the skills which employers look for, and which lead to satisfying international careers. The new type of academic mobility abroad leads to gains in academic, cultural, intercultural, linguistic, personal and professional domains, and confers a competitive advantage when it comes to finding a first or subsequent job. The skills acquired, and the enhanced employability which they bring, are explicitly recognized by researchers, by graduates themselves, by Government, and by employers. The advantage applies to graduates in both languages and other specialisms (Coleman, 2011).

Before I embark on the analysis of the new model of academic mobility I would like to provide some theoretical underpinning regarding the concept of "employability". Employability is defined as a set of achievements, - skills, understandings and personal attributes that make graduates more likely to gain employment and be successful in their chosen occupations, which benefits themselves, the workforce, the community and the economy. Employability skills - group of essential abilities that involve the development of a knowledge base, expertise level and mindset that is increasingly necessary for success in the modern workplace. Employability skills are typically considered essential qualifications for many job positions and hence have become necessary for an individual's employment success at just about any level within a business environment.

While there is no singular definition of employability, a review of the literature suggests that employability is about work and the ability to be employed, such as: 1) the ability to gain initial employment; hence the interest in ensuring that 'key skills', careers advice and an understanding about the world of work are embedded in the education system; 2) the ability to maintain employment and make 'transitions' between jobs and

${ }^{*}$ S.Vincent-Lancrin, 2012. Higher education for innovation societies, OECD, based on REFLEX and HEGESCO data 
roles within the same organization to meet new job requirements, and 3) the ability to obtain new employment if required, i.e. to be independent in the labor market by being willing and able to manage their own employment transitions between and within organizations.

It is also, ideally, about the quality of such work or employment. People may be able to obtain work but it may be below their level of skill, or in low paid, undesirable or unsustainable jobs, and so forth; the capacity and capability of gaining and maintaining productive work over the period of one's working life (Hillage and Pollard 1998)

There are four components of employability that new employees should poses:

Assets. An individual's 'employability assets' comprise their knowledge (i.e. what they know), skills (what they do with what they know) and attitudes (how they do it).

Deployment. These are a linked set of abilities which include career management skills, self-awareness, decision-making skills, transition skills, job search skills, strategic approach, etc.

Presentation. Another key aspect of employability is being able to get a particular job, once identified - sometimes included under career management skills, but is given prominence as a separate element here due to its crucial importance to securing employment. It centres around the ability to demonstrate 'employability' assets and present them to the market in an accessible way.

In the context of personal circumstances and the labour market. Finally and crucially, the ability to realize or actualize 'employability' assets depends on the individual's personal and external circumstances and the inter-relationship between the two.

Development of four components of employability is quite challenging. It sets the tasks not only for students, but also for educational institutions, companies and the government.

One of the possible answers to the challenges is international mobility within Erasmus Mundus "Triple I"* and "Aurora" Mundus "Triple I" is built along the traditional model of mobility. The mobility is arranged between 10 universities in Russia and 10 universities in Europe.

Triple I mobility scheme consists of 226 grantees. Mobility is open to all disciplines that fit the theme Integration, Interaction and Institutions. By this principle a vast applicant potential is to be reached.

The proposal of mobility flows by type is as follows: UG 34\%, MA 26\%, Doc 20\%, Post Doc 7\% and staff 13\%. Russian grantees represent $76 \%$ of all the proposed 226 mobilities. Of these Russian mobilities, TG3 forms $5 \%$ and TG2 22\%. TG1 represents $73 \%$ of all third country

* Erasmus Mundus “Triple I” website: http://www.utu.fi/en/sites/iii/Pages/home.aspx.

${ }^{\dagger}$ Erasmus Mundus "Aurora” website: http://www3.utu.fi/sivustot/em-aurora/.

-61 - 
mobilities These mobility flows promote multilateral cooperation between partners. The students and staff in host and home universities benefit from the mobility scheme as they come into contact with people from other linguistic and cultural environment. Through the mobility scheme the society is enriched by open-minded and internationally experienced academics and students. This will also increase links between Europe and Russia in all spheres of society thus contributing to cultural dialogue and mutual understanding.

The target groups of Triple $I$ have a substantial influence on the development of Euro-Russian relations in the future. Students are the future decision makers and policymakers, politicians, officials and civil servants in regional, national and international levels. Staff members contribute to the development of the students as well as to the curricula of the universities. Through TG2 and TG3 Triple I have an immediate effect on the entire Russian society.

Experiences of individual grantees contribute to institutional development: host universities benefit academically from exchange of experience and good practices in pedagogy and research. In addition, host and home universities receive new ideas on how to broaden the curricula and courses offered for students. Faculties/departments at host universities adapt their procedures to accommodate an increasing flow of foreign students, developing new courses ministered in English and/or adapting existing courses to allow for tutoring and evaluation in English when appropriate, even when teaching is given in a local language. These results contribute to the development of both home and host universities: experiences of grant holders lead to higher degree of innovation in teaching and research and increase international cooperation capacity on personal and institutional level.

Triple $I$ aim at the development of joint research projects and promotes exchange of experience in educational methods and practices. The grantees in all target groups become accustomed to different teaching technologies and learning environments, thus enjoy increased learning skills. In addition, organising individual mobilities enhances multilateral cooperation in university administration which helps disseminate the outcomes in a sustainable way. This includes development of mobility administration and utilizing ECTS, in particular. The aim is also to develop recognition of studies and qualifications, especially in those Russian universities not already using ECTS in full scale.

The new Erasmus Mundus "Aurora" project recognizes the importance of the interaction between higher education and the labor market and surrounding society, in order to promote knowledge transfer and graduates' employability. In order to develop, societies require individuals capable of producing new knowledge, new ideas and insights instead of re-producing already existing knowledge and procedures. Higher education does not in itself produce expertise - it however builds capacity for individuals to become experts in their field. In the process of education, talented individuals acquire the capacity to develop 
transferable skills such as theoretical knowledge, critical thinking and research capacity, which are essential prerequisites in the development of expertise.

The theme of the Consortium is University-Business Cooperation. Aurora aims at opening a continuous dialogue between Europe and Russian in the field of university and business. It promotes knowledge transfer between universities and entrepreneurs by creating framework for partnership, joint projects and exchange of people.

Mobility scheme consists of 236 grantees. Of these grant holders $70 \%$ represent Russia. Partner universities' students and staff represent $52 \%$ of the mobilities. The Consortium aims at sustainable cooperation by emphasizing doctorate, post-doctorate and staff mobilities. These mobilities represent nearly $52 \%$ of the total mobility flow. Researchers, teachers and administrative staff contributes to the development of joint research projects and promote exchange of experience in innovations, business, and educational methods and practices.

Aurora mobility scheme is based on free mobility. This means that applicants to the mobility scheme in all target groups can apply freely to any European/Russian partner university of their interest. Free mobility and lack of pre-assigned mobility quotas allow the mobilities to be chosen on academic criteria. The thematic expertise of each partner can be fully appreciated and the interests of the applicants served. The Consortium aims at multilateral mobility flows that arise from academic interest.

A growing number of students in higher education (research universities and universities of applied sciences) have the opportunity to put their knowledge into practice by means of a work placement. While the importance of placements is increasingly emphasized in education policy and teaching inspections, there is still a considerable lack of knowledge regarding placement procedures among placement coordinators, lecturers, and placement providers. After all, students have the world at their feet, and this is especially true of students on placement: so many organizations, so many placements. As long as the level and extent of the placement meet the requirements, virtually anything is possible. A work placement differs from other degree programme components in that students are often required to look for a placement themselves. This and the fact that placements deal with a third party outside university makes it difficult for degree programme organizers to arrange this non-traditional type of subject into their curriculum (Haag, 2012).

For that reason, in every degree programme, a placement is a subject in itself. No other course component unit offers students so much freedom yet presents so many difficulties: freedom because placements, by definition, largely take place beyond the lecturer's reach; difficulties because placements are carried out completely unaided. A student will be asked to complete his/her placement independently and to comply with the wishes of two different parties, and the requirements of his/her 
degree programme often differ considerably from those of a student's placement provider.

The only proper way of looking at a placement, therefore, is to consider it a project with the student as project leader. It is a project with a learning objective, an assignment, and a plan. The project has two supervisors: the lecturer and the supervisor within the host organization. It is emphasized that all placement projects that are not assessed by a lecturer, and are therefore not rewarded with credits, are beyond the scope of the present article.

As an example of good practice of arranging work placements mention should be made of the systems developed at the Faculty of Arts at the University of Groningen, one of the members of Aurora consortium. The system consists of eight steps:

1. Orientation which contains learning outcomes, placement assignment criteria, etc.

2. Self-analysis which aims at defining student's generic competences and personal profile and his/her needs

3. Market analysis which contains the analyses of sector and industry, position and placement assignments

4. Networking

5. Applying for a placement which presupposes writing an application letter for an advanced position, knowledge of language of the other culture and basic CV

6. Preparation for the interview

7. The placement. It presupposes placement plan, placement position, duration of the placement, financial aspects, etc.

8. Rounding off student's placement. It includes placement report and final evaluation by the placement provider, by the lecturer and the student (Haag, 2012).

A placement is no static entity; its organization requires flexibility, which is why the order of steps is not completely fixed. The reason for this is that the steps allow for a certain degree of interaction: after Step 3, the student might feel the need to return to Step 1, etc.

Naturally, the steps a student takes and the order in which he/she takes them largely depend on his/her degree programme.

Another example of good practice can be illustrated by the University of Nordland (Norway). In order to apply for the placement a student should enclose a copy of the ECTS student placement file. The file should contain the following documents:

- Transcript of records provided by the applicant institution before the mobility period

- Training agreement and quality commitment. This agreement indicates subject areas and mobility period. The host institution lists the tasks of the employee and skills required to be able to complete the placement period successfully. This agreement is signed by all 
three parties: the home institution, the host institution and the student.

The pre- and post approval document should include the following components:

- Harmonization of the studies in metrology in three cycle degree system according to Bologna process

- In the file the student should mention that he/she will conduct his/her placement abroad as part of his/her BA/MA degree

- It is also important to include in the file a paragraph explaining that the placement will be evaluated by three written reports from the student

- Normally the placement abroad equals to 20 ECTS

- In the confirmation from the host organization mention should be made of the variety of tasks that the student has performed. There should be also a paragraph confirming the tasks had been monitored with close collaboration with the other office employees, quality assuring his/her work and that he/she has performed his/her tasks with a satisfactory quality without any problem

- The student should receive the confirmation from the host organization, which in addition to the reports required from the student to the faculty, will be the documentation needed to start the post approval processes

All the above mentioned components are pre- and post procedures the faculty uses, regardless of where the student conduct his/her placement period*.

Thus, emerging forms of academic mobility seem more interesting than conventional forms. "This is because the open-ended contingent complexity that characterizes multidimensional academic mobility has existed for decades, yet we know virtually nothing about it; compared with the types of mobility connected to performance indicators and tracked in statistics" (Hoffman, 2009).

Among the new models of academic mobility of the future is ICTbased mobility. As an example of such kind of mobility mention should be made of the "ShanghAI Lectures" $\dagger$ project which is run by the University of Zurich. It unites 16 universities worldwide with Russian State University for the Humanities as the only Russian participant in the project. These lectures about natural and artificial intelligence are held via videoconference at the University of Zurich in Switzerland, the University of Salford/MediaCityUK in the United Kingdom, Shanghai Jiao Tong University in China, and other universities around the globe. The project makes education and knowledge on cutting-edge scientific topics accessible to everyone, explores novel methods of knowledge transfer, overcomes the complexity of a multi-cultural and

* Explanatory notes to ECTS student placement file. University of Nordland, Norway. 16.02.2012.

+ "ShanghAI Lectures" website: http://shanghailectures.org 
interdisciplinary learning context and brings global teaching to a new level.

There are more questions and answers regarding the meaning the academic mobility will take on during the several decades of the $21^{\text {st }}$ century. We think it is justified to develop a multi-modal prospective to academic mobility with a multiplicity of research methods.

\section{References}

Coleman, J., 2011. Study/work abroad and employability, Shaping the future, University council of modern languages (UCML), Retrieved 12.04.2013 from http://www.ucml.ac.uk/sites/default

/files/shapingthefuture/102/20\%20\%20jim\%20coleman\%2ointer\%2oresource\%2otemplate -o.pdf

Haag, E., 2012. Internship guide. Work placements step by step, Hague: Eleven international publishing

Hillage, J., Pollard, E., 1998. Employability: Developing a framework for policy analysis, Research Brief, No.85, Department for Education and Employment

Hoffman, David M., 2009. Changing academic mobility. Patterns and international. migration. What will academic mobility mean in the 21st century? Journal of studies in international education published online, Vol.13, pp.347-64, Retrieved 12.04.2013 from http://jsi.sagepub.com/content/13/3/347.full.pdf

Vincent-Lancrin, S. 2012. Higher education for innovation societies, OECD, based on REFLEX and HEGESCO data 